\title{
Energy restriction initiated at different gestational ages has varying effects on maternal weight gain and pregnancy outcome in common marmoset monkeys (Callithrix jacchus)
}

\author{
Suzette Tardif*, Michael Power, Donna Layne, Darlene Smucny and Toni Ziegler \\ Southwest National Primate Research Center, PO Box 760549, San Antonio, TX 78245-0549, USA
}

(Received 14 April 2004 - Revised 30 July 2004 - Accepted 3 August 2004)

\begin{abstract}
With relatively high fertility and short lifespan, marmoset monkeys (Callithrix jacchus) may become useful primate models of prenatal nutritional effects on birth condition and adult disease risk. The present study determined the effects of energy restriction to $75 \%$ of expected ad libitum consumption during mid- (day 66) or late (day 99) gestation on maternal weight, fetal growth and pregnancy outcomes in this species. Mid-restriction reliably induced the loss of pregnancy before term, at $92 \mathrm{~d}$, on average. Of the late-restricted pregnancies, four of seven were normal term length while three were preterm deliveries, at 101, 117 and $132 \mathrm{~d}$. Control females had a mean mid-pregnancy weight gain of $0.67 \mathrm{~g} / \mathrm{d}$ while mid-restricted females lost $-0.65 \mathrm{~g} / \mathrm{d}$, on average. Control pregnancies averaged a $1.06 \mathrm{~g} / \mathrm{d}$ gain during late pregnancy, while energy-restricted females lost $-0.67 \mathrm{~g} / \mathrm{d}$, on average. Restriction-related weight change was highly variable, ranging from +0.55 to $-2.56 \mathrm{~g} / \mathrm{d}$ for mid-restriction pregnancies and from +0.79 to $-3.91 \mathrm{~g} / \mathrm{d}$ for late-restriction pregnancies. For mid-restriction pregnancies, the number of restriction days was best explained by linear weight change and total weight loss while the number of restriction days in late pregnancy was best explained by linear weight change alone. In late-restriction pregnancies, smaller females had higher daily weight losses. Restrictions did not induce litter-size reduction or growth restriction in those infants that were delivered at term but the size of aborted fetuses suggested that at least some pregnancies lost preterm may have involved impaired intra-uterine growth.
\end{abstract}

Energy restriction: Maternal weight: Pregnancy: Primates: Birth weight

There is a developing interest in new models of intra-uterine growth. Restricted growth, in utero, results in low birth weight and low birth weight is related to an increased risk for death, impaired postnatal development and preterm delivery (Hediger et al. 1995; Doubilet et al. 2003).

In addition to the effects of intra-uterine growth restriction on preterm delivery and the immediate risks associated with low birth weight, epidemiological studies suggest relationships between low birth weight and an increased risk for a variety of adult-onset diseases (Barker, 2001; Godfrey \& Barker, 2001). These findings have led to heightened interest in this area, including the development of numerous hypotheses of mechanism, all of which would benefit from the development of animal models.

The restriction of maternal energy or protein availability as a means to generate growth restriction in utero has been examined in a variety of animal models. The species most commonly used for such studies is the rat (Lederman \& Rosso, 1980; Lee et al. 1980; Reynolds et al. 1984; Rudge et al. 1997; Chisari et al. 2001; Bayol et al. 2004). However, the effects of nutritional restrictions have also been examined in other species, including sheep (Pond et al. 1989; Edwards et al. 2001), pigs (Pond et al. 1988) and guinea-pigs (Kind et al. 1995). While the insights to be gained from these models are many, each has limitations if the ultimate goal is to apply the results to man, given the differences in placentation, prenatal growth patterns and mechanisms associated with parturition among mammalian taxa (for example, see Challis et al. 2000; Pere, 2003).

Primate models of fetal growth restriction are extremely limited. Schroder (2003) identified 1406 published animal experiments on fetal growth restriction. Of those experiments, approximately $73 \%$ were performed on rats or mice. Only $0.6 \%$ (eight out of 1406) of the identified animal experiments on intra-uterine growth restriction were performed on non-human primates. Studies specifically on the effects of energy or energy-protein restriction during gestation in primates are even more limited. Kohrs et al. (1976) examined the effects of a low-protein diet in rhesus monkeys, finding that restricting protein content to $25 \%$ of normal resulted in no weight gain in the mothers, significantly more preterm deliveries, and half of the pregnancies producing stillbirths or infants that were dead shortly after delivery. Birth weights of live-born, term infants (born from day 160 to 167) were about $10 \%$ lower for the dams fed the low-protein diet.

Two uniquely primate aspects of pregnancy (fetal adrenal zone production of oestrogen substrates and placental 
production of corticotrophin-releasing hormone (CRH)) make the development of primate models to test findings from non-primate species important. For example, recent studies by Bloomfield et al. (2003b) propose that undernutrition of ewes during very early pregnancy can reprogramme fetal hypothalamic-pituitary-adrenal axis maturation, resulting in premature delivery. However, it is clear that the interplay of the placenta and the fetus in fetal hypothalamic-pituitary-adrenal maturation is probably quite different in primates and non-primates. Therefore, the replication of these studies in a primate model is a critical step in assessing their importance for the understanding of human parturition. The design of such a study would benefit from an initial characterisation of the response of primates to energy restriction during gestation. Specifically, it is unclear whether the types of energy restrictions that reliably generate effects on intra-uterine growth and birth condition in species that have relatively high daily investments in intra-uterine growth would also generate such effects in primates, a taxonomic group with a generally lower daily investment in intrauterine growth.

Common marmoset monkeys (Callithrix jacchus) offer a particularly valuable opportunity to develop useful primate models of prenatal effects on birth condition and ultimately on adult disease risk, given that they have the highest fertility and shortest average and maximum lifespan of any anthropoid primate. The first ovulatory cycles occur at about 12-15 months of age and sexual maturity is complete at 21 months, on average (Abbott et al. 2003). The average lifespan for a captive marmoset that survives infancy is approximately 6 years (Tardif et al. 2003) and the maximum lifespan is about 15 years. Marmosets can be considered aged at around 8 years of age. This contrasts with the lifespan of a macaque or baboon, in which sexual maturity is reached at 3-4 years of age, the average lifespan exceeds 15 years and old age is not reached until 20-25 years.

The goal of the present study was to determine the effects of an energy restriction that is considered moderate in rodent and sheep models on maternal weight, fetal growth and pregnancy outcomes in the common marmoset, a small non-human primate. Because studies in rats and human subjects suggest that the timing of nutritional restrictions during gestation may strongly affect outcome, we examined restrictions during both mid-gestation and late gestation.

\section{Methods}

The subjects of the present study were twenty-three captive common marmoset females who bred between October 1999 and February 2004, producing fifty-eight pregnancies during that time period. All pregnancies used in these analyses were from females who weaned viable offspring at least twice. Nine of the multiparous females were subjected to energy restrictions during one to three pregnancies. For the five females subjected to more than one restriction, the order of presentation of restrictions was roughly balanced (three first received a mid-pregnancy restriction and two first received a late pregnancy restriction). There was no evidence of restriction effects extending beyond the period of restriction - i.e. all restricted females produced viable deliveries following restrictions and there was no evidence of increased inter-birth intervals or other effects on pregnancy outcomes in pregnancies that followed a completed restriction period. Subjects were assigned to control and restriction regimens in a manner that resulted in no significant differences in average pre-pregnancy weights or maternal age among groups (see Table 1).

All experimental and control subjects were fed either of two purified diets, specifically formulated for these studies (Tardif et al. 1998a). One diet was formulated to provide approximately $15 \%$ of estimated metabolisable energy from protein and the other to provide $25 \%$ (see Table 2). Previously, we demonstrated that normal reproduction can be sustained with either of these two purified diets (Tardif et al. 1998a, 2001). Our initial restriction regimen was based on findings from other species in which limiting pregnant females to $75 \%$ of expected ad libitum energy consumption is considered a moderate restriction (Lee et al. 1980; Reynolds et al. 1984; Pond et al. 1989; Kind et al. 1995; Edwards et al. 2001; Bayol et al. 2004).

Table 1. Comparison of maternal weight and age in restricted and non-restricted pregnancies

(Mean values and standard deviations)

\begin{tabular}{|c|c|c|c|c|c|}
\hline \multirow[b]{2}{*}{ Treatment } & \multirow[b]{2}{*}{$n$} & \multicolumn{2}{|c|}{$\begin{array}{l}\text { Pre-pregnancy } \\
\text { weight }(\mathrm{g})\end{array}$} & \multicolumn{2}{|c|}{$\begin{array}{c}\text { Maternal age } \\
\text { at delivery } \\
\text { (years) }\end{array}$} \\
\hline & & Mean & SD & Mean & SD \\
\hline None & 38 & 381.9 & $51 \cdot 1$ & $3 \cdot 32$ & 0.93 \\
\hline $\begin{array}{l}\text { Ad libitum } \\
\text { separation-fed } \\
\text { control }\end{array}$ & 5 & $380 \cdot 6$ & $61 \cdot 7$ & $2 \cdot 83$ & 0.33 \\
\hline $\begin{array}{l}\text { Mid-term } \\
\quad \text { energy restriction }\end{array}$ & 8 & 384 & 53.4 & 3.35 & 1.06 \\
\hline $\begin{array}{l}\text { Late-term } \\
\quad \text { energy restriction }\end{array}$ & 7 & 398 & $76 \cdot 91$ & 3.87 & 0.29 \\
\hline
\end{tabular}

Table 2. Nutrient composition (DM basis) of the two diets used in the study*

\begin{tabular}{|c|c|c|c|}
\hline Nutrient & $\begin{array}{l}\text { Formulated } \\
\text { concentration }\end{array}$ & Nutrient & $\begin{array}{c}\text { Formulated } \\
\text { concentration }\end{array}$ \\
\hline Vitamin A $(\mu \mathrm{g} / \mathrm{kg})$ & 4500 & Protein $(\%) \dagger$ & 15 or 25 \\
\hline Vitamin $D_{3}(\mu \mathrm{g} / \mathrm{kg})$ & 225 & Fat $(\mathrm{g} / \mathrm{kg})$ & 56 \\
\hline Vitamin $\mathrm{E}(\mathrm{mg} / \mathrm{kg})$ & 100 & $\mathrm{Ca}(\mathrm{g} / \mathrm{kg})$ & 12 \\
\hline Vitamin C (mg/kg) & 1000 & $P(g / k g)$ & 8 \\
\hline Vitamin $\mathrm{K}(\mathrm{mg} / \mathrm{kg})$ & 5 & $\mathrm{Na}(\mathrm{g} / \mathrm{kg})$ & 3 \\
\hline Riboflavin (mg/kg) & 7 & $\mathrm{~K}(\mathrm{~g} / \mathrm{kg})$ & 10 \\
\hline Niacin $(\mathrm{mg} / \mathrm{kg})$ & 60 & $\mathrm{Mg}(\mathrm{g} / \mathrm{kg})$ & 1.5 \\
\hline Thiamin (mg/kg) & 30 & $\mathrm{Fe}(\mathrm{mg} / \mathrm{kg})$ & 250 \\
\hline Vitamin $\mathrm{B}_{6}(\mathrm{mg} / \mathrm{kg})$ & 15 & $\mathrm{Cu}(\mathrm{mg} / \mathrm{kg})$ & 15 \\
\hline Folic acid (mg/kg) & 2 & $\mathrm{Zn}(\mathrm{mg} / \mathrm{kg})$ & 60 \\
\hline $\begin{array}{l}\text { Pantothenic } \\
\text { acid }(\mathrm{mg} / \mathrm{kg})\end{array}$ & 35 & $\mathrm{Mn}(\mathrm{mg} / \mathrm{kg})$ & 30 \\
\hline Biotin (mg/kg) & 0.3 & $\mathrm{Se}(\mathrm{mg} / \mathrm{kg})$ & 0.2 \\
\hline Vitamin $B_{12}(\mu \mathrm{g} / \mathrm{kg})$ & 50 & $\mathrm{I}(\mathrm{mg} / \mathrm{kg})$ & 0.5 \\
\hline
\end{tabular}

*Ingredients: lactalbumin, dextrin, sucrose, mineral and vitamin mixes specifically formulated for the diet, soyabean oil, cellulose, choline bitartrate, tertiary butyl hydroquinone (antioxidant).

$\dagger$ Expressed as the percentage of estimated metabolisable energy, assuming 17,17 and $38 \mathrm{~kJ} / \mathrm{g}$ for protein, carbohydrate and fat, respectively. 
Expected ad libitum consumption was estimated from the results of a series of $2 \mathrm{~d}$ feeding trials on females in this population using this diet, as well as published estimates of energy intake in pregnant marmoset females (Nievergelt \& Martin, 1999). The relative intake during pregnancy was similar between the two colonies, averaging $619 \mathrm{~kJ} / \mathrm{kg}$ body weight in our colony and $660 \mathrm{~kJ} / \mathrm{kg}$ in the Nievergelt \& Martin (1999) study. Restricted females were, therefore, provided with $464 \mathrm{~kJ} / \mathrm{kg}$ body weight per $\mathrm{d}$. They were fed the $25 \%$ protein diet, resulting in their protein consumption being roughly equivalent to that of ad libitum-fed females who were fed the $15 \%$ protein diet. Although the nutrient requirements of marmosets are not completely characterised, the diets were formulated such that all other nutrients in the diet (for example, $\mathrm{Ca}, \mathrm{Fe}$, folic acid, vitamins $\mathrm{B}_{6}$ and $\mathrm{B}_{12}$ ) were in sufficient excess that a $75 \%$ restriction would still probably provide adequate nutrition. This judgement was based on values published in the most recent National Research Council publication on nutrient requirements for non-human primates (National Research Council Committee on Animal Nutrition, 2003).

It was not necessary to measure maternal food consumption in the restricted groups, as all females consumed all of the diet presented to them on each day of restriction. Thus, all females were restricted to a known energy intake, based on their pre-pregnancy weight, which was $75 \%$ of the expected intake for a female of their body mass. Estimating the restricted energy intake by comparison with published or population means of ad libitum consumption is a commonly used method in the pregnancy-restriction studies of other species such as rats (Lederman \& Rosso, 1980; Lee et al. 1980; Rudge et al. 1997), guinea-pigs (Kind et al. 1995) and sheep (Edwards \& McMillen, 2001; Bispham et al. 2003; Bloomfield et al. 2003a,b).

Control of food intake was accomplished by separating females on one side of the double-unit home cage. Females had visual, olfactory, auditory and limited tactile access to the other members of their family group through a mesh door dividing the two units. A control group of pregnant females ( $n$ 5) was fed in the same fashion as restricted females, but given ad libitum access to food, to determine whether the feeding separation, in and of itself, had an effect on maternal weight gain and pregnancy outcome. Females were separated from the group from 08.0017.00 hours, Sunday to Thursday and throughout Friday to Saturday. During the period that restrictions were conducted, there were thirty-eight pregnancies in which females were unmanipulated but monitored in a fashion identical to that of restricted or separation-fed females.

All females were given an ultrasound examination every 2 weeks to determine stage of pregnancy and the size and condition of embryos or fetuses. Gestational age was estimated by embryonic crown-rump lengths taken during the early, rapid phase of growth in crown-rump length, between days 55 and 70. This measure can be used to consistently estimate delivery dates (Tardif et al. 1998b). Measures of biparietal diameter and abdominal circumference were also made at later gestational ages (day 100 or greater). After day 50, the maximum number of heartbeats observed at ultrasound was used to estimate maximum litter size, in utero. This litter size was then compared with birth litter size to determine whether in utero littersize reduction had occurred.

Maternal weights and birth-condition measurements were made in a fashion identical to the methods used routinely for non-manipulated pregnancies in this colony. Maternal weights were measured, on average, once weekly, using the methods described by Tardif et al. (2001) except for restricted females who were, on average, weighed twice weekly. Briefly, weights were taken by placing a scale in the animal's home cage - i.e. animals did not have to be handled for weighing. Changes in maternal weight during mid- (day 60-100) or late (day 93-140) pregnancy were determined by linear regression of maternal weight on gestational day. The slope of this regression (if $P<0 \cdot 15$ ) was then used as an estimator of average weight change across the time period in question. If the regression had a $P>0 \cdot 15$, the slope was estimated as 0 . A probability of $P=0.15$ was used in order to include weight changes that were likely to be biologically significant but were not strictly linear across the entire period. Infants were removed at approximately $36 \mathrm{~h}$ following delivery. Infants were weighed, measured and tests of motor skills were conducted, as described by Tardif et al. (2002). Infants that were found dead before $36 \mathrm{~h}$ were weighed and measured when found. The floor of the cages and the floor under the cages were inspected each morning for signs of pregnancy loss (i.e. blood or aborted material). Any aborted fetuses or placenta were collected, measured and weighed.

Marmoset gestation is reported to average 143 or $144 \mathrm{~d}$ (Hearn, 1986; Jaquish et al. 1995), with implantation occurring at about day $10-11$, followed by a largely quiescent period with slow cell division and differentiation until around day 50, at which point developmental processes speed up and organogensis is completed by day 80 (Chambers \& Hearn, 1985; Merker et al. 1988). Restriction was initiated at two time points - mid-gestation $(n 8)$ and late gestation ( $n$ 7). Mid-restriction began at estimated gestational ages ranging from 60 to $72 \mathrm{~d}$ (mean $66.9 \mathrm{~d}$ ). The mid-restriction, therefore, began during the middle to late period of organogenesis. During this period there is an exponential increase in placental weight. Late restriction began at estimated gestational ages ranging from 92 to $105 \mathrm{~d}$ (mean 99d). By day 99, growth in the placental area is largely complete, though placental size continues to increase at a slowed pace throughout the rest of gestation. Growth in fetal weight is most rapid at this phase.

The effects of the energy-restriction treatments on maternal weight gain, day of gestation at delivery, litter size, infant size (body weight, biparietal diameter, kneeheel length, and abdominal circumference) and infant behavioural skills were examined. The effects of restriction on day of gestation at delivery, linear weight change and infant-size measures were evaluated using generalised linear model analyses, with litter size and maternal age as covariates and maternal identity as a random factor. Within each restriction group, a backward regression was used to examine the relationship of number of days between the initiation of restriction and pregnancy loss to the following maternal weight variables: pre-pregnant weight; linear weight change; total weight change. While 
all fifty-eight pregnancies were used in the analyses as a whole, not all measures were available for all pregnancies, due to occasional missed samples or sampling errors. Specific sample sizes are provided in the tables and figures for each parameter.

\section{Results}

Ad libitum-separation-fed females did not differ from unmanipulated females in any variable (delivery age $F$ $0.824, P=0.46$; maternal weight change (Kruskall-Wallis test) $F 0.228-0.773, P=0.379-0.653$; infant size measures $F 0-2 \cdot 04, P=0.986-0 \cdot 196)$. This indicates that the process of separating the females for feeding did not affect maternal weight or pregnancy outcome. For further analyses, ad libitum-separation-fed and unmanipulated pregnancies were combined as a single control group.

Energy restrictions in both mid- and late pregnancy had significant effects on the length of pregnancy $(F 32 \cdot 14$, df 3, $P<0.0001$ - see Fig. 1). Mid-restriction reliably induced the loss of pregnancy before term. The majority of mid-restricted pregnancies (six of eight) were lost to follow-up - i.e. the pregnancy loss was identified when the female was pregnant, with live fetuses, at one ultrasound and not pregnant, with no placenta or fetuses identified in the uterus, at an ultrasound 2 weeks later. The day of pregnancy loss in these cases was designated as midway between these two ultrasound examinations. Pregnancy loss occurred at an estimated 11 to $47 \mathrm{~d}$ following the initiation of restriction (mean 25 (SD 11.08) d). The average estimated gestational age of pregnancy loss was $92 \mathrm{~d}$. Of the late-restricted pregnancies, $57 \%$ (four of seven) were normal term length while three were preterm deliveries, at 101, 117 and $132 \mathrm{~d}$.

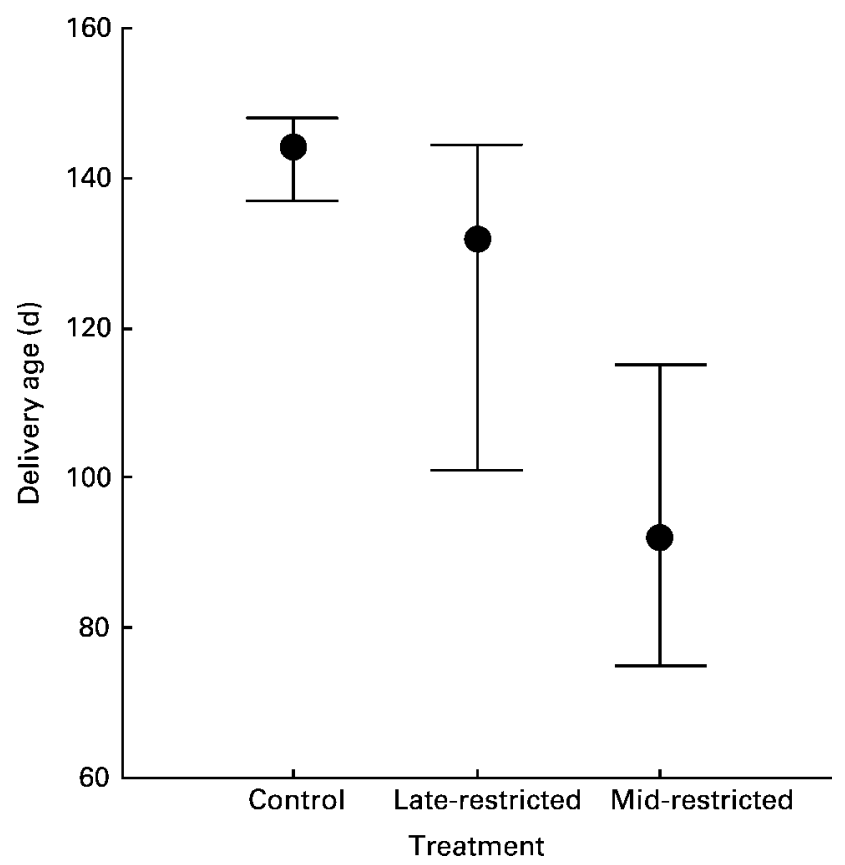

Fig. 1. Estimated gestational age at delivery for control ( $n$ 22), midrestricted $(n 8)$ and late-restricted $(n 7)$ pregnancies. Mean values are shown, with ranges represented by vertical bars.
There were no pregnancy losses from 60 to $130 \mathrm{~d}$ for the control pregnancies. Pregnancy losses associated with restriction were unrelated to the female's reproductive performance when unrestricted - i.e. all subjects had viable, term deliveries during unmanipulated pregnancies both preceding and following restricted pregnancies.

The weight change of the restricted females was compared with the weight change of the control females - see Fig. 2. During the period of pregnancy encompassing mid-restriction (day 60-100), the control females had a mean weight gain of 0.67 (SD 0.08) g/d while the midrestricted females had a mean weight loss of -0.65 (SD $0.42) \mathrm{g} / \mathrm{d}$. The difference between these two groups was significant $(F 8.515$, df $2, P<0.006)$. During the period encompassing late restriction (day 93-140), the mean weight gain of the controls was $1.06(\mathrm{SD} 0.20) \mathrm{g} / \mathrm{d}$ while the restricted females had a mean weight loss of -0.67 (SD 0.65) g/d ( $F 5.05$, df $1, P<0.073$ ). Weight gain and gestational age at delivery for the control subjects were unrelated.
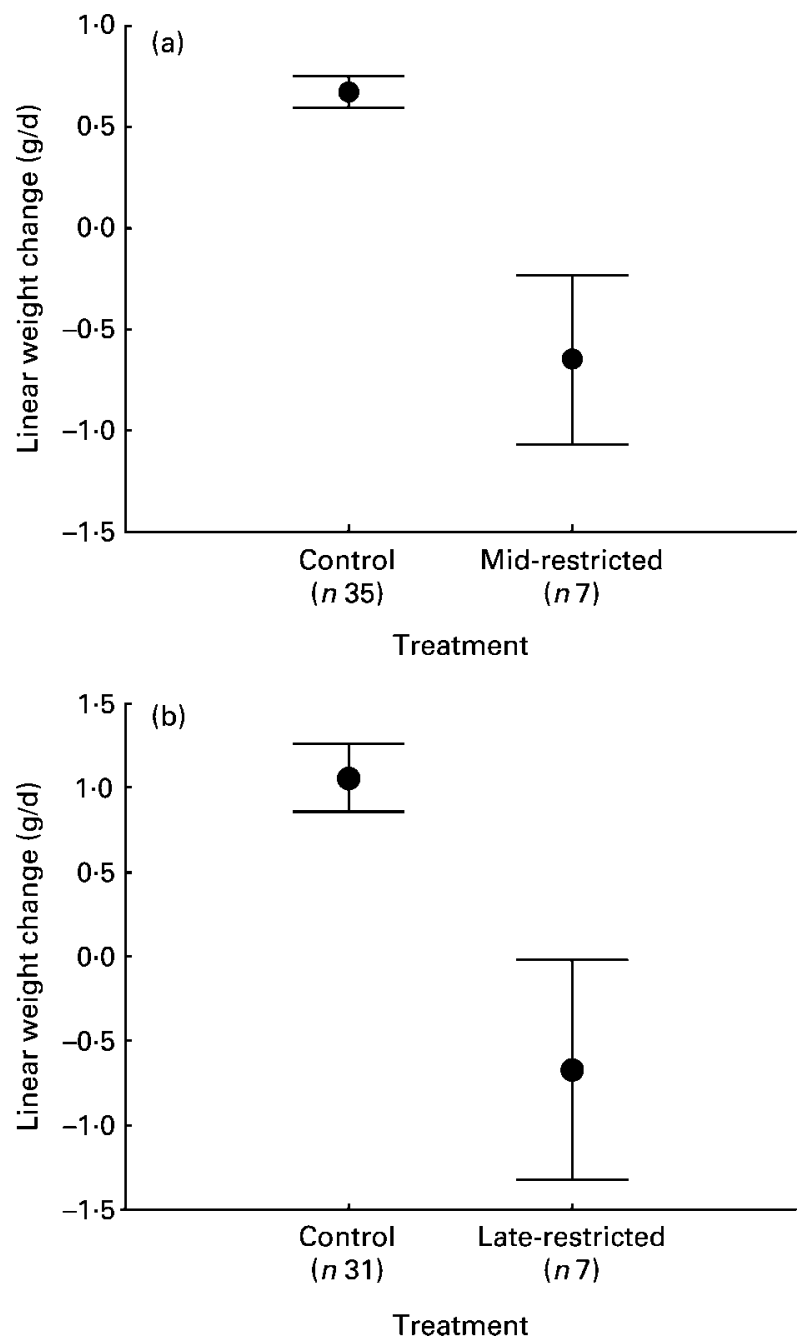

Fig. 2. Weight change $(\mathrm{g} / \mathrm{d})$ as estimated by linear regression for (a) control and mid-restricted pregnancies for days 60-100 and (b) control and late-restricted pregnancies for days 93-140. Mean values are shown, with their standard errors represented by vertical bars. 
While the overall pattern of weight change in restricted pregnancies differed or tended to differ from control pregnancies, weight change in both restriction regimens was highly variable, ranging from +0.55 to $-2.56 \mathrm{~g} / \mathrm{d}$ for mid-restriction pregnancies and from +0.79 to $-3.91 \mathrm{~g} / \mathrm{d}$ for late-restriction pregnancies. Fig. 3 presents the length of time from the initiation of restriction to pregnancy loss in mid-restriction pregnancies $v$. linear weight change and total weight change. For mid-restriction pregnancies, the number of restriction days was best explained by linear weight change and initial weight (adjusted $R^{2}$ $0.447, F 3.828, P=0.09$ ), with pre-pregnancy weight being non-significant. It appears that restriction pregnancies might be divided into two groups, those in which there was $>10 \%$ weight loss and those with $<10 \%$ weight loss while, within both groups, higher daily weight loss was associated with earlier pregnancy loss. Fig. 4 presents restriction days $v$. linear weight change for late-restriction pregnancies. In this case, the number of restriction days was best explained by linear weight change alone (adjusted $R^{2} 0 \cdot 778, F 14.99, P=0.03$ ), with pre-pregnancy weight and total weight loss being non-significant. However, pre-pregnancy weight was significantly correlated with linear weight change (Pearson correlation (r) $0.78, P=0.04)$; smaller females had higher daily weight losses.

Litter size was unaffected by restriction. There were forty-five pregnancies (thirty-three control, five midrestriction, seven late-restriction) with litter sizes between one and three for which ultrasound data were deemed sufficient to estimate litter size in utero. For those pregnancies, litter size was erroneously underestimated in $6.9 \%$ of litters, an error value similar to that reported previously by using these same methods (Jaquish et al. 1996). There were $20.9 \%$ of pregnancies in which there was a potential litter-size reduction in utero - i.e. the maximum estimated

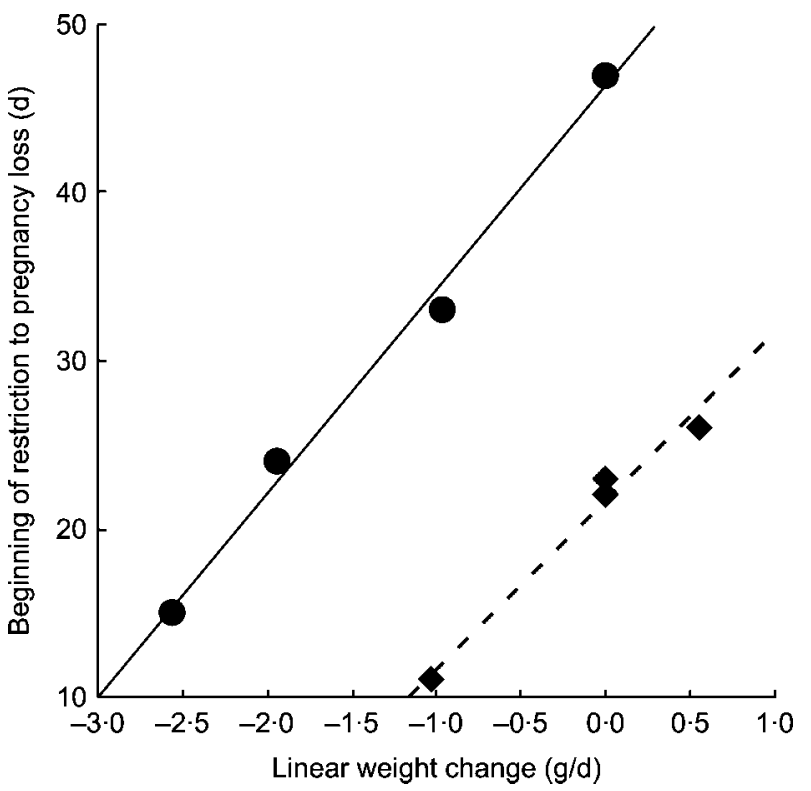

Fig. 3. Weight change $(\mathrm{g} / \mathrm{d}) \mathrm{v}$. days on restriction for mid-restricted pregnancies, coded by overall weight loss $(--\bullet--, 1-8 \%$ loss $(0-31 \mathrm{~g}) ;-0-,>10 \%$ loss $(39-60 \mathrm{~g}))$.

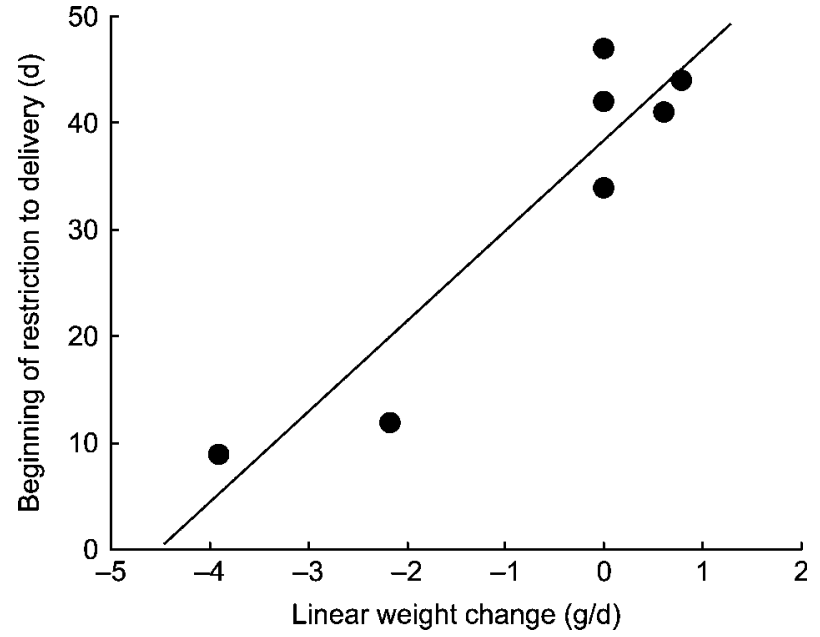

Fig. 4. Weight change $(\mathrm{g} / \mathrm{d}) \mathrm{v}$. days on restriction for late-restricted pregnancies.

litter size in utero was larger than the birth litter size or there was identification of a reduction in the number of heartbeats observed from one ultrasound to the next. The percentage of pregnancies in which there was a potential in utero litter-size reduction was higher for energyrestricted pregnancies $(33 \%)$ than for control pregnancies $(15 \%)$, but the difference was not statistically significant $\left(\chi^{2} 1 \cdot 82\right.$, df $\left.1, P=0 \cdot 178\right)$.

For mid-term-restricted pregnancies, the crown-rump length and biparietal diameter of the fetuses, as measured during the last pregnant ultrasound, did not differ from measurements expected for that gestational age. Changes in abdominal circumference, prenatally, were also compared in late-restriction and control pregnancies. Abdominal circumference growth across gestational ages 100$140 \mathrm{~d}$ did not differ between control and restricted pregnancies.

While ultrasound measures did not suggest intra-uterine growth restriction for either restriction regimen, fetal weights and measures of aborted material recovered from mid-restriction pregnancies were lower than expected, based on published measures of timed-collected fetuses (Chambers \& Hearn, 1985) - see Table 3. Placental weight was also less than expected based upon published measures $(2.13$ v. $4.6 \mathrm{~g}$ expected $)$; however, the placental disk areas $\left(3.44-4.51 \mathrm{~cm}^{2}\right)$ were similar to the expected area $\left(4.87 \mathrm{~cm}^{2}\right)$. The size of the fetuses (weight, biparietal diameter and knee-heel length) for preterm-delivered infants of late-restricted mothers were close to expected values for the day 132 delivery, but the weights were substantially smaller than expected for the day 117 delivery (no fetuses were recovered from the day 101 delivery) see Table 3.

Table 4 provides information on birth-condition measures for control infants and infants resulting from late-restriction pregnancies. The statistical significance of the difference between the control pregnancies and the late-restricted pregnancies on all measures ranged from $P<0.055$ to 0.096 , suggesting that, with a larger sample size, one might detect a difference between these two groups. However, a comparison of outcome of control 
Table 3. Birth-size measures for preterm deliveries from restricted dams

\begin{tabular}{|c|c|c|c|c|c|c|c|c|c|}
\hline \multirow[b]{2}{*}{ Treatment } & \multirow{2}{*}{$\begin{array}{l}\text { Estimated age } \\
\text { at delivery }(d)\end{array}$} & \multicolumn{2}{|c|}{ Weight (g) } & \multicolumn{2}{|c|}{$\mathrm{CRL}(\mathrm{mm})$} & \multicolumn{2}{|c|}{$\mathrm{BPD}(\mathrm{mm})$} & \multicolumn{2}{|c|}{$\mathrm{KHL}(\mathrm{cm})$} \\
\hline & & Actual & Expected* & Actual & $\overline{\text { Expected }}$ & Actual & $\overline{\text { Expected }}$ & Actual & Expected \\
\hline Mid-restriction & 95 & $1.45-1.70$ & 3.27 & - & - & $5.97-7.77$ & $10 \cdot 75$ & $0.43-0.53$ & 0.87 \\
\hline Late-restriction & 117 & $7 \cdot 17-8 \cdot 51$ & $14 \cdot 6$ & - & - & $14 \cdot 2-14 \cdot 6$ & $16 \cdot 3$ & $1 \cdot 22-1 \cdot 27$ & 1.67 \\
\hline Late-restriction & 132 & $20 \cdot 0-24 \cdot 8$ & $20 \cdot 8$ & - & - & $16 \cdot 8-17 \cdot 5$ & $18 \cdot 0$ & $1.80-1.94$ & 1.95 \\
\hline
\end{tabular}

CRL, crown-rump length; BPD, biparietal diameter; KHL, knee-heel length.

${ }^{*}$ Expected values taken from Chambers \& Hearn (1985).

Table 4. Comparison of birth-size measures for control and late-restriction pregnancies

(Mean values and standard deviations for control pregnancies and within-litter ranges for five restriction pregnancies for which measures were available)

\begin{tabular}{|c|c|c|c|c|c|c|c|c|c|c|c|}
\hline \multirow[b]{2}{*}{ Treatment } & \multicolumn{2}{|c|}{$\begin{array}{l}\text { Delivery } \\
\text { age (d) }\end{array}$} & \multirow[b]{2}{*}{ LS } & \multicolumn{2}{|c|}{ Birth weight (g) } & \multicolumn{2}{|c|}{$\begin{array}{c}\text { Biparietal } \\
\text { diameter }(\mathrm{mm})\end{array}$} & \multicolumn{2}{|c|}{$\begin{array}{l}\text { Knee-heel } \\
\text { length }(\mathrm{cm})\end{array}$} & \multicolumn{2}{|c|}{$\begin{array}{l}\text { Abdominal circum- } \\
\text { ference }(\mathrm{mm})\end{array}$} \\
\hline & Mean & SD & & Mean & SD & Mean & SD & Mean & SD & Mean & SD \\
\hline \multirow[t]{2}{*}{ Control } & 144.9 & $2 \cdot 76$ & 2 & $29 \cdot 33$ & 2.49 & $19 \cdot 78$ & 0.61 & $2 \cdot 25$ & 0.09 & $60 \cdot 47$ & 4.49 \\
\hline & $143 \cdot 0$ & $3 \cdot 14$ & 3 & 28.09 & $3 \cdot 21$ & $19 \cdot 04$ & 0.84 & $2 \cdot 17$ & 0.12 & $59 \cdot 82$ & 5.00 \\
\hline \multirow{4}{*}{ Late restriction } & 117 & & 3 & $7 \cdot 17-8 \cdot 51$ & & $14 \cdot 17-14.57$ & & $1 \cdot 22-1 \cdot 27$ & & $34.5-36.5$ & \\
\hline & 132 & & 3 & $20 \cdot 0-24 \cdot 8$ & & $16 \cdot 8-17.5$ & & $1.80-1.94$ & & $42 \cdot 5-57 \cdot 0$ & \\
\hline & 144 & & 2 & $29 \cdot 0-30 \cdot 0$ & & $19 \cdot 6-19 \cdot 9$ & & $2 \cdot 15-2 \cdot 25$ & & $59 \cdot 5-61.5$ & \\
\hline & 144 & & 2 & $29 \cdot 0-30 \cdot 0$ & & $20 \cdot 1-20 \cdot 2$ & & $2 \cdot 28-2 \cdot 33$ & & $57 \cdot 0-59.5$ & \\
\hline
\end{tabular}

LS, litter size.

and restricted pregnancies matched by dam identity and litter size suggested that any differences are accounted for by the fact that some late-restriction pregnancies resulted in preterm deliveries - i.e. infants from term deliveries of late-restricted dams did not differ from control infants of the same litter size. Infants of late-restricted mothers that were delivered at term also did not differ from control infants in scores of motor and sensory capability.

\section{Discussion}

The results of a relatively modest energy restriction of pregnant marmosets suggest that this species is particularly sensitive to restriction during mid-gestation, a period during which the placenta is undergoing exponential growth. All pregnancies restricted at mid-term were lost significantly before term and none resulted in live deliveries. Most of the pregnancy losses were probably associated with fetal demise in utero. In contrast, there were no pregnancy losses before term when the females were fed ad libitum, either separately or in their social group. The fact that there were no pregnancy losses in the day 60-130 range in the control group indicates that neither separation of dams for feeding nor routine handling for ultrasonography interfered with normal gestation.

The loss of all pregnancies associated with a $25 \%$ restriction of energy is a more extreme finding than that reported for most studies of rodents or sheep (Pond et al. 1989; Kind et al. 1995; Edwards et al. 2001). While it is difficult to determine, for most studies, what percentage of pregnancies terminated preterm due to nutritional restrictions, some studies do report that a reduction of litter size and occurrence of the complete loss of litters through fetal reabsorption or abortion is more common in energy- or protein-restricted rodents than in non-restricted animals. However, most studies do report the majority of restricted subjects maintaining pregnancies to term or near-term (Pond et al. 1989; Kind et al. 1995; Rudge et al. 1997). There was no evidence in the present study that restricted dams were more likely to have in utero litter-size reductions than were control females, suggesting that the mechanisms controlling restriction effects tended to result in either no change or complete loss of the pregnancy.

The results of the present study are similar to the study by Kohrs et al. (1976). In that study, feeding a severely protein-restricted diet to pregnant macaques eliminated the normal maternal weight gain of pregnancy, greatly increased the chance of preterm deliveries, but had only a modest effect (10\% reduction) on birth weight for infants born at term $(160-167 \mathrm{~d})$.

Marmosets have an unusual pattern of prenatal development, involving extremely slow development between implantation at day 11-12 and day 50. For example, the onset of limb-bud development in man and old-world monkeys, such as macaques and baboons, occurs early at about day 25-30 but not until day 50 in the marmoset (Merker et al. 1988). Following this point, the curve composed of time to developmental stage runs parallel for man and marmosets. Therefore, for mid-restricted pregnancies, the average estimated gestational age of pregnancy loss of $92 \mathrm{~d}$ would be roughly equivalent to 14 weeks in a human pregnancy. The latest estimated gestational age at which a midterm-restricted pregnancy was lost was approximately 
$115 \mathrm{~d}$, roughly equivalent to 25 weeks in a human pregnancy.

The mean weight gains observed in the control females, in mid- and late pregnancy, respectively, were 0.674 and $1.06 \mathrm{~g} / \mathrm{d}$. These can be contrasted with weight gains described for pregnant captive marmosets by Nievergelt \& Martin (1999) of approximately 0.71 and $0.74 \mathrm{~g} / \mathrm{d}$ in mid- and late gestation, respectively, and those of an earlier report by Lunn (1983) of 0.39 and $1.30 \mathrm{~g} / \mathrm{d}$. The differences across these studies may be related to the females' initial weights; the females in Lunn's study began pregnancy at a significantly lighter weight (averaging about $320 \mathrm{~g}$ ) compared with those in the Nievergelt \& Martin (1999) study (averaging $418 \mathrm{~g}$ ), while the present study consisted of females between these two extremes (averaging $382 \mathrm{~g}$ ).

Energy restriction during both mid- and late gestation reliably prevented the weight gains that were seen in the control pregnancies; however, weight changes were highly variable among restricted subjects. This difference was not accounted for by the female's pre-pregnancy weight in mid-pregnancy; however, in late pregnancy, there was a relationship between initial maternal weight and weight change, with smaller females more likely to lose more weight per d. Studies of rodents suggest that high weight protects against restriction-induced abortion (Reynolds et al. 1984; Pond et al. 1989). In the present study, such protection may have occurred in late but not mid-pregnancy.

The variable weight change associated with restriction may have resulted from a number of causes that are not mutually exclusive. Females may have differed in energy output and the extent to which they modified such output while restricted. Food intake while not pregnant may vary in marmosets to the extent that matching each female to her own consumption patterns in preceding pregnancies will be advisable in future studies. Mid-restriction pregnancies could be divided into those in which there appeared to be less 'tolerance' for the procedure, with subjects losing pregnancies relatively early and with no to moderate weight loss and those with more 'tolerance' for the procedure, with subjects losing pregnancies over a wider range of gestational ages, associated with significant weight loss. No variable has been identified that distinguished these two groups - i.e. they did not differ in maternal age, parity, initial weight or genetic relatedness, though perhaps with larger sample sizes, effects of these variables will be found.

Low maternal weight, low BMI and poor weight gain are associated with low birth weight and preterm delivery in macaques (McFarland, 1997) and man (for example, (Ehrenberg et al. 2003) in retrospective studies. A recent retrospective human study also suggests differential relationships of maternal weight gain during different periods of gestation to pregnancy outcome. An examination of weight gain by trimester (Brown et al. 2002) found that weight gain in the first and second trimester was predictive of infant birth weight, but that weight gain in the third trimester was not. Ponderal index (weight-for-length) was strongly predicted by weight gain in the first trimester but not by weight gain in the second trimester and only weakly by weight gain in the third trimester. Maternal weight loss in the first trimester was significantly associated with smaller infants at birth, either by weight or by ponderal index. Such results from retrospective studies leave open the possibility that the maternal weight loss and poor pregnancy outcome are simply tied to a third unidentified factor (for example, infection) that is responsible for both. The present study reinforces the proposition that maternal weight loss or lack of weight gain, in and of itself, may affect pregnancy outcome in primates.

There was substantial evidence that both mid- and lateterm energy restrictions resulted in preterm delivery in marmosets, but there was little evidence that energy restriction produced intra-uterine growth restriction in pregnancies that proceeded to term. In those pregnancies, infant size measures were comparable with controls. In addition, ultrasound measures of fetal size (biparietal diameter and abdominal circumference) in restricted pregnancies did not differ from measures expected at that gestational age. For pregnancies that were lost preterm and from which fetal material was collected (two mid-restricted and two late-restricted), the weights and length measures of the fetuses were in three cases substantially lower than expected, based on published measures of fetuses collected throughout gestation (Chambers \& Hearn, 1985). These results could mean that in utero growth restriction occurred but that all intra-uterine growth-restricted pregnancies were associated with preterm loss. However, the recovered fetuses had probably died in utero and were in various stages of maceration and possible reabsorption, making interpretation of size measures problematic.

The pregnancy losses associated with this mid-term energy restriction could be the result of a number of different mechanisms and some of those mechanisms might be distinguished by comparison of maternal endocrine changes during restriction. For example, energy restriction could act as a stressor resulting in increasing maternal cortisol concentration and increasing placental CRH production (or decreasing production of CRH binding protein); increased $\mathrm{CRH}$ would, in turn, result in an increased fetal adrenal production of dehydroepiandrosterone sulfate. This would lead to increased oestradiol production by the placenta, triggering changes in prostaglandin function, leading to the onset of contractions and delivery. Conversely, energy restriction could result in (1) a decrease in placental CRH production which might adversely affect fetal adrenal development or (2) hypoxic conditions favouring reduced insulin-like growth factor (IGF)-1 and increased IGF binding protein, ultimately leading to reduced placental growth and fetal demise - either of these cases would be associated with decreasing maternal serum concentrations of cortisol and oestradiol. The limited nature of the information available on these restricted pregnancies means we were unable to conclusively distinguish between these mechanisms. However, urinary concentrations of oestrogens, cortisol and chorionic gonadotropin during the 2 weeks preceding mid-restriction pregnancy loss were compared in six subjects for which there were matching data on control pregnancies that proceeded to term ( $\mathrm{S}$ Tardif, $\mathrm{T}$ Ziegler, $\mathrm{D}$ Layne \& M Power, unpublished results). Concentrations of oestradiol, cortisol and chorionic gonadotropin were all lower 
in the restricted pregnancies than during control pregnancies at the same estimated gestational age. These results suggest that the restriction does not act as a classical stressor and that perhaps the endocrine function of the placenta is rapidly impaired by the restriction. However, it may be the case in marmosets, as it is in sheep, that the length of nutritional restriction affects maternal and fetal endocrine response. Bloomfield et al. (2003a) reported that short-term undernourishment of ewes $(10 \mathrm{~d})$ results in elevated maternal cortisol concentrations while longer undernourishment $(>20 \mathrm{~d})$ results in reduced circulating cortisol. Therefore, a finergrained analysis of endocrine differences in the first week of restriction $v$. the later period might indicate a similar biphasic effect in the marmoset. Future studies will examine potential endocrine mechanisms associated with energy restriction-induced loss, including alterations in placental $\mathrm{CRH}$ production and alterations in IGF-IGF binding protein function in both mother and fetus.

\section{References}

Abbott DH, Barnett DK, Colman RJ \& Schultz-Darken NJ (2003) Aspects of basic biology and life history of common marmosets important for biomedical research. Comp Med 53, 339-350.

Barker DJ (2001) The malnourished baby and infant. Br Med Bull 60, 69-88.

Bayol S, Jones D, Goldspink G \& Stickland N (2004) The influence of undernutrition during gestation on skeletal muscle and on the expression of genes that control muscle growth. $\mathrm{Br} J$ Nutr 91, 331-339.

Bispham J, Gopalakrishnan GS, Dandrea J, Wilson V, Budge H, Keisler DH, Broughton Pipkin F, Stephenson T \& Symonds ME (2003) Maternal endocrine adaptation throughout pregnancy to nutritional manipulation: consequences for maternal plasma leptin and cortisol and the programming of fetal adipose tissue development. Endocrinol 144, 3575-3585.

Bloomfield FH, Oliver MH, Giannoulias D, Gluckman PD, Harding JE \& Challis JRG (2003a) Brief undernutrition in late-gestation sheep programs the hypothalamic-pituitaryadrenal axis in adult offspring. Endocrinol 144, 2933-2940.

Bloomfield FH, Oliver MH, Hawkins P, Campbell M, Phillips DJ, Gluckman PD, Challis JRG \& Harding JE (2003b) A periconceptional nutritional origin for noninfectious preterm birth. Science 300, 606.

Brown J, Murtaugh M, Jacobs D \& Margellos H (2002) Variation in newborn size according to pregnancy weight change by trimester. Am J Clin Nutr 76, 205-209.

Challis JRG, Matthews SG, Gibb W \& Lye SJ (2000) Endocrine and paracrine regulation of birth at term and preterm. Endocr Rev 21, 514-550.

Chambers PL \& Hearn JP (1985) Embryonic, foetal and placental development in the common marmoset monkey (Callithrix jacchus). J Zool Lond 207, 545-561.

Chisari A, Biovambattista N, Perello M \& Spinedi E (2001) Impact of maternal undernutrition on hypothalamo-pituitaryadrenal axis and adipocyte functions in male rat offspring. Endocrine 14, 375-382.

Doubilet PM, Benson CB, Wilkins-Haug L \& Ringer S (2003) Fetuses subsequently born premature are smaller than gestational age-matched fetuses not born premature. J Ultrasound Med 22, 359-363.

Edwards L, Coulter C, Symonds M \& McMillen I (2001) Prenatal undernutrition, glucocorticoids and the programming of adult hypertension. Clin Experim Pharmacol Physiol 28, 938-941.
Edwards LJ \& McMillen IC (2001) Maternal undernutrition increases arterial blood pressure in the sheep fetus during late gestation. J Physiol 533, 561-570.

Ehrenberg H, Dierker L, Milluzzi C \& Mercer B (2003) Low maternal weight, failure to thrive in pregnancy and adverse pregnancy outcomes. Am J Obstet Gynecol 189, $1726-1730$.

Godfrey KM \& Barker DJ (2001) Fetal programming and adult health. Public Health Nutr 4, 611-624.

Hearn JP (1986) The embryo-maternal dialogue during early pregnancy in primates. $J$ Reprod Fertil 76, 809-819.

Hediger ML, Scholl TO, Schall JI, Miller LW \& Fischer RL (1995) Fetal growth and the etiology of preterm delivery. Obstet Gynecol 85, 175-182.

Jaquish C, Tardif S, Toal RL \& Carson RL (1996) Patterns of prenatal survival in the common marmoset (Callithrix jacchus). J Med Primatol 25, 57-63.

Jaquish C, Toal RL, Tardif S \& Carson RL (1995) Use of ultrasound to monitor prenatal growth and development in the common marmoset (Callithrix jacchus). Am J Primatol 36, 259-275.

Kind KL, Owens JA, Robinson JS, Quinn KJ, Grant PA, Walton PE, Gilmour RS \& Owens PC (1995) Effect of restriction of placental growth on expression of IGFs in fetal sheep: relationship to fetal growth, circulating IGFs and binding proteins. J Endocrinol 146, 23-34.

Kohrs MB, Harper AE \& Kerr GR (1976) Effects of a low-protein diet during pregnancy of the rhesus monkey I. Reproductive efficiency. Am J Clin Nutr 29, 136-145.

Lederman S \& Rosso P (1980) Effects of food restriction on fetal and placental growth and maternal body composition. Growth 44, 77-88.

Lee M, Eguchi Y, Arishima K \& Chan K-Y (1980) Compensatory adrenal hypertrophic response in fetuses of calorie-malnourished rats. Biol Neonate 37, 153-157.

Lunn SF (1983) Body weight changes throughout pregnancy in the common marmoset Callithrix jacchus. Folia Primatol (Basel) 41, 204-217.

McFarland R (1997) Female primates: fat or fit? In The Evolving Female, pp. 163-175 [M Morbeck, A Galloway and A Zihlman, editors]. Princeton, NJ: Princeton University Press.

Merker HJ, Sames K, Csato W, Heger W \& Neubert D (1988) The embryology of Callithrix jacchus. In Non-Human Primates - Developmental Biology and Toxicology, pp. 217-239 [D Neubert, H-J Merker and AG Hendrickx, editors]. Berlin: Ueberreuter-Wissenschaft.

National Research Council Committee on Animal Nutrition (2003) Nutrient Requirements of Nonhuman Primates, 2nd revised ed. Washington, DC: National Academy Press.

Nievergelt CM \& Martin RD (1999) Energy intake during reproduction in captive common marmosets (Callithrix jacchus). Physiol Behav 65, 849-854.

Pere M (2003) Materno-foetal exchanges and utilisation of nutrients by the foetus: comparison between species. Reprod Nutr Dev 43, 1-15.

Pond W, Mersmann H, Yen J \& Daris W (1989) Reproduction and organ weight responses in female rats fed a restricted balanced diet or a restricted nonprotein calorie diet with or without supplemental glutamine or cysteine. Growth Reprod Devel 53, 17-24.

Pond W, Yen J \& Mersmann H (1988) Maternal tissue re-partitioning in pregnant primiparous swine in response to restriction of calories or feed. Proc Soc Exp Biol Med 188, $128-135$.

Reynolds L, Ho H \& Taper L (1984) Effect of caloric restriction during pregnancy on maternal and fetal body composition in the obese Sprague-Dawley rat. J Nutr 114, $2247-2255$. 
Rudge MV, Gomes CM, Calderon Ide M, Ramos MD, Abbade JF, de Oliveira MG \& da Silva MG (1997) Study of the evolution of the placenta and fetal pancreas in the pathophysiology of growth retardation intrauterine due to restricted maternal diet. Sao Paulo Med J 117, 49-56.

Schroder HJ (2003) Models of fetal growth restriction. Eur J Obstet Gynecol Reprod Biol 110, Suppl. 1, S29-S39.

Tardif S, Jaquish C, Layne D, Bales K, Power M, Power R \& Oftedal O (1998a) Growth variation in common marmoset monkeys (Callithrix jacchus) fed a purified diet: relation to care-giving and weaning behaviors. Lab Anim Sci 48, 264-269.

Tardif S, Layne D, Cancino L \& Smucny DA (2002) Neonatal behavioral scoring of common marmosets (Callithrix jacchus): relation to physical condition and survival. J Med Primatol 31, $147-151$.

Tardif S, Power M, Oftedal O, Power R \& Layne D (2001) Lactation, maternal behavior and infant growth in common marmoset monkeys (Callithrix jacchus): effects of maternal size and litter size. Behav Ecol Sociobiol 51, 17-25.

Tardif SD, Jaquish CE, Toal RL, Layne DG \& Power RA (1998b) Estimation of gestational ages in the common marmoset (Callithrix jacchus) from published prenatal growth curves. J Med Primatol 27, 28-32.

Tardif SD, Smucny DA, Abbott DH, Mansfield K, SchultzDarken N \& Yamamoto ME (2003) Reproduction in captive common marmosets (Callithrix jacchus). Comp Med 53, $364-368$. 